\title{
The prevalence of the metabolic syndrome and associated cardiovascular complications in adult-onset GHD during GH replacement: a KIMS analysis
}

\author{
Johan Verhelst' ${ }^{1}$, Anders F Mattsson ${ }^{2}$, Cecilia Camacho-Hübner ${ }^{3}$, Anton Luger ${ }^{4}$ and Roger Abs ${ }^{5}$ \\ ${ }^{1}$ Department of Endocrinology, ZNA Middelheim Hospital, Antwerp, Belgium \\ ${ }^{2}$ Pfizer Endocrine Care, Pfizer Health $A B$, Sollentuna, Sweden \\ ${ }^{3}$ Pfizer Endocrine Care, Pfizer, Inc., New York, New York, USA \\ ${ }^{4}$ Division of Endocrinology and Metabolism, Medical University and General Hospital, Vienna, Austria \\ ${ }^{5}$ Antwerp Centre for Endocrinology, Antwerp, Belgium \\ Correspondence should be addressed to J Verhelst: johan.verhelst@zna.be
}

\begin{abstract}
Background: Adult-onset growth hormone deficiency (AO-GHD) is associated with an increased prevalence of the metabolic syndrome (MetS).

Aim: To determine the effect of GH replacement on the prevalence of MetS in AO-GHD and to study the impact of MetS on the incidence of cardiovascular events during $\mathrm{GH}$ replacement.

Patients and methods: 1449 AO-GHD patients (males $48.9 \%$; mean age $48.9 \pm 12.8$ year) were retrieved from KIMS (Pfizer International Metabolic Database). The prevalence of MetS (using International Diabetes Federation criteria) and its components were calculated at baseline and after one year of GH replacement. The relative risk to develop cardiovascular events according to the presence of MetS at baseline was assessed in another group of 3282 patients after prolonged GH replacement.

Results: The prevalence of MetS was $46.9 \%$ at baseline and $48.2 \%$ after one year of GH replacement $(P=\mathrm{NS})$. The percentage of patients with abnormal waist circumference decreased significantly ( 80.3 vs $77.4 \% ; P<0.001)$, but impaired glucose metabolism (17.1 vs $23.3 \% ; P<0.001$ ) increased and HDL cholesterol (48.2 vs $50.9 \% ; P=0.011$ ) decreased. Switch from MetS to NoMS (18.5\%) and from NoMS to MetS (18.8\%) occurred. All patients showed a significant and comparable amelioration of quality of life. During seven years of GH replacement patients with MetS had a $66 \%$ higher risk $(P=0.0016)$ to develop a new coronary disease compared to NoMS.

Conclusion: MetS prevalence remains unchanged in AO-GHD during one year of GH replacement whereas its components are differentially affected. Besides GH replacement, consequent pharmacotherapy of all risk factors and endorsement of lifestyle intervention appears to be of uttermost importance together with early GHD diagnosis to prevent cardiovascular disease during prolonged treatment.
\end{abstract}

\author{
Key Words \\ - metabolic syndrome \\ - hypopituitarism \\ - growth hormone \\ deficiency \\ - GH replacement \\ - cardiovascular disease
}

Endocrine Connections (2018) 7, 653-662

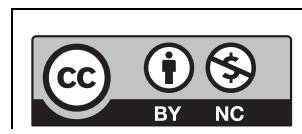

This work is licensed under a Creative Commons Attribution-NonCommercial 4.0 International
License. http://www.endocrineconnections.org https://doi.org/10.1530/EC-18-0096
(C)2018 The authors Published by Bioscientifica Ltd 


\section{Introduction}

It is now well-recognized that patients with adult-onset growth hormone deficiency (AO-GHD), apart from experiencing a poor quality of life (QoL), present with an increased risk of developing a metabolic syndrome (MetS) $(1,2,3,4)$. MetS describes the clustering of five cardiovascular risk factors: increased waist circumference due to visceral fat accumulation, elevated blood pressure, lowered HDL cholesterol, increased triglycerides, and impaired glucose tolerance and is considered an important predictor of cardiovascular disease $(5,6)$. There are different MetS definitions, of which the revised National Cholesterol Education Program (NCEP) and the International Diabetes Federation (IDF) are most commonly used $(7,8)$. It is estimated that now about one third of the European adult population has MetS according to the IDF criteria and that both males and females with MetS are about 1.5 times more likely to die from cardiovascular complications (9).

Patientswith AO-GHDhavea prevalenceof MetSbetween 1.3- and 2-fold that of the general population $(1,4)$ and this varies depending on the studies between 31.0 and $56.6 \%$ (1, $2,3,4)$. The elevated MetS prevalence in GHD is probably of particular relevance as an increased cardiovascular mortality has been found in patients with hypopituitarism receiving conventional hormonal replacement without GH (10, 11, 12). A recent KIMS study assessing GHD patients with MetS before $\mathrm{GH}$ replacement also reported a higher prevalence ratio (PR) of coronary and cerebrovascular morbidity compared to patients without MetS (3). It has clearly been documented that GH replacement had a favourable effect on QoL and on the different MetS components, apart from a possible deterioration of the glycaemic control, particularly in patients with elevated BMI $(13,14,15,16)$. However, no study assessing the occurrence of MetS during GH replacement has so far indicated any improvement in its prevalence $(1,2,4)$. Furthermore, the impact of GH replacement on the increased cardiovascular mortality is unsettled $(4,17)$.

The first aim of the present study was to use the KIMS (Pfizer International Metabolic Database) in order to investigate the effect of one year of GH replacement on the prevalence of MetS and of its components in the largest available cohort of AO-GHD patients. The subsequent aim was to characterize and compare the two groups of patients who changed their MetS status during this period. The final objective was to assess the incidence of cardiovascular and cerebrovascular events occurring during the whole follow-up period of GH replacement.

$$
\text { http://www.endocrineconnections.org }
$$

\section{Patients and methods}

\section{Patients}

In the prevalence analysis were included: patients of European origin with severe AO-GHD confirmed by an accepted GH stimulatory test, naïve or semi-naïve (without GH replacement for at least 6 months prior to study entry) to GH replacement, with a complete set of data on the five MetS components at baseline (BL) and after 1 year of GH replacement (Y1). A total of 1449 patients fulfilled the inclusion criteria for this study. Females numbered 740 (51.1\%; mean age, $47.7 \pm 12.8$ year), divided into age categories $<40$ year $(n=216), 40-60$ year $(n=386)$, $>60$ year $(n=138)$ and males numbered $709 \quad(48.9 \%$; mean age, 50.2 \pm 12.7 year), divided into age categories $<40$ year $(n=158), 40-60$ year $(n=380)$, $>60$ year $(n=171)$. The group with MetS consisted of 679 patients (46.9\%; mean age, $51.1 \pm 12.1$ year), while the group without MetS (NoMS) consisted of 770 patients (53.1\%; mean age, $47.0 \pm 13.1$ year).

The cardiovascular complications analysis consisted of patients recruited according to the same inclusion criteria, except for the addition of non-naïve patients (already on GH replacement at baseline). A total number of 3282 patients (50.2\% females) fulfilled the inclusion criteria for this study. The MetS group consisted of 1516 patients ( $46.2 \%$; mean age, $51.1 \pm 12.0$ year; mean duration of follow-up, $6.8 \pm 4.7$ year; number of patientyears, 10373), while the NoMS group consisted of 1766 patients (53.8\%; mean age, $46.6 \pm 13.1$ year; mean duration of follow-up, 7.8 \pm 5.1 year; number of patientyears, 13713).

Informed consent was obtained from patients in accordance with local regulations. The studies were performed in accordance with the Declaration of Helsinki (18). The data collection into KIMS was approved by the ZNA/OCMW Antwerp Institutional Review Boards/ Ethical Committees as required by local regulations in each participating country. Written informed consent was obtained from all the patients before any data were entered into KIMS.

\section{Methods}

Background and baseline data consisted of gender, age, medical history (hypertension, hyperlipidaemia, diabetes mellitus), BMI, blood pressure and waist circumference. Plasma glucose was measured at the site of the participating centres, while serum lipids (total cholesterol, HDL cholesterol, triglycerides) were

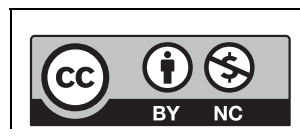

This work is licensed under a Creative Commons Attribution-NonCommercial 4.0 International License. 
performed in a central laboratory according to welldefined methods (3). Serum IGF-I was measured centrally using methods detailed in previous KIMS publications (3). Quality of life was assessed by the QoL-AGHDA questionnaire, which scores ranges from 0 to 25 , with the higher score corresponding to a poorer quality of life (19). All these parameters have been determined at BL and Y1. The GH dose used at one year of replacement was also retrieved from the database.

\section{Definition of MetS}

The diagnosis of MetS was defined according to the IDF criteria (8). Central obesity (defined by a waist circumference $\geq 94 \mathrm{~cm}$ for males and $\geq 80 \mathrm{~cm}$ for females) plus any two of the following four factors: a blood pressure $\geq 130 / 85 \mathrm{mmHg}$ or the use of anti-hypertensive drugs, a serum high-density cholesterol $\leq 40 \mathrm{mg} / \mathrm{dL}(1.0 \mathrm{mmol} / \mathrm{L})$ for males and $\leq 50 \mathrm{mg} / \mathrm{dL}$ $(1.3 \mathrm{mmol} / \mathrm{L})$ for females or the use of lipid-lowering drugs, serum triglycerides $\geq 150 \mathrm{mg} / \mathrm{dL}(1.7 \mathrm{mmol} / \mathrm{L})$ or the use of lipid-lowering drugs, raised fasting glucose $>100 \mathrm{mg} / \mathrm{dL}$ $(5.6 \mathrm{mmol} / \mathrm{L})$ or type 2 diabetes (defined by a random or $2 \mathrm{~h}$ OGTT glucose $\geq 200 \mathrm{mg} / \mathrm{dL}$ ( $11.1 \mathrm{mmol} / \mathrm{L})$; a HbA1c $\geq 6.4 \%$ or the use of anti-diabetic drugs (20). The MetS score, ranging between 0 and 5 , corresponds to the sum of the abnormal MetS components, with the higher score denoting the most adverse MetS profile.

\section{Study design}

The MetS PR, comparing MetS prevalence after 1 year of GH replacement with the MetS prevalence at KIMS entry before $\mathrm{GH}$ replacement, was first calculated for the whole group of patients, and then separated by gender and age. Similarly, the prevalence of the five separate MetS components was determined before and after 1 year of GH replacement, crude and by age and gender categories. The relative impact of the separate MetS components upon the global MetS score was calculated. Additionally, the absolute changes in the five components between MetS patients and NoMS patients at baseline were compared.

Four groups of patients, corresponding to retention or change of their MetS status during GH replacement, were characterized by the MetS score and its components, and by related factors, such as changes in BMI, IGF-I and QoLAGHDA. Significant differences between the two groups with MetS status reversal were calculated.

All patients, irrespective of GH replacement naïvety and with complete data on MetS components, were followed up to the occurrence of a new specific cardiovascular or cerebrovascular event, or to the reported date of last visit or date of death. The incidence rates of these complications occurring in the group of MetS patients at baseline were compared to the group of NoMS patients.

\section{Statistics}

Changes in the prevalence of MetS after 1 year of GH replacement were assessed. The change was expressed as percentage change or as the ratio of the prevalence at the 1-year visit and the prevalence at KIMS entry (start of $\mathrm{GH}$ replacement). Analyses were also performed based on the 4 possible transition groups (i.e. 2 groups where no change in MetS status was observed and 2 groups where MetS status changed between the 2 time points).

Results are expressed as counts and percentage for categorical variables and as mean \pm s.D. for numerical variables. The McNemar's test for paired samples was used in the crude analysis to analyse the changes during $\mathrm{GH}$ replacement in the prevalence of MetS, as well as on the different MetS components (waist, blood pressure, HDL cholesterol, triglycerides and glucose). In the multiple regression analyses of $\mathrm{PR}$ at the 1-year visit compared to $\mathrm{BL}$ visit, Robust Poisson regression methods with repeated measurements were applied, with adjustment for age and gender. In the quantitative analyses of change between visits in MetS components, multiple linear regression was performed with adjustment for gender and age. In special analyses, end-point specific drug therapy at baseline was incorporated as a potential confounding indicator variable. Estimates are presented with 95\% confidence intervals (CIs) and statistical significance was set to 5\%. SAS v9.2 Proc Genmod (SAS Inc., Cary, NC, USA) was used.

\section{Results}

Prevalence of MetS and of its components during one year of $\mathrm{GH}$ replacement

The number of MetS patients increased at Y1 from 679 to $698(46.9 \%$ vs $48.2 \%$; $P=\mathrm{NS})$, corresponding to an increase of $3 \%(95 \% \mathrm{CI},-2 \%$ to $8 \%)$ or a PR increase of 1.03 (95\% CI, 0.98-1.08). When separated by age and gender, a significant increase was noticed in MetS for males $>60$ year and females $<40$ year, while a decrease was only noted in males $<40$ year and between 40 and 60 year, although the difference was not significant (Fig. 1). http://www.endocrineconnections.org https://doi.org/10.1530/EC-18-0096
(C)2018 The authors Published by Bioscientifica Ltd
This work is licensed under a Creative Commons Attribution-NonCommercial 4.0 International License. 


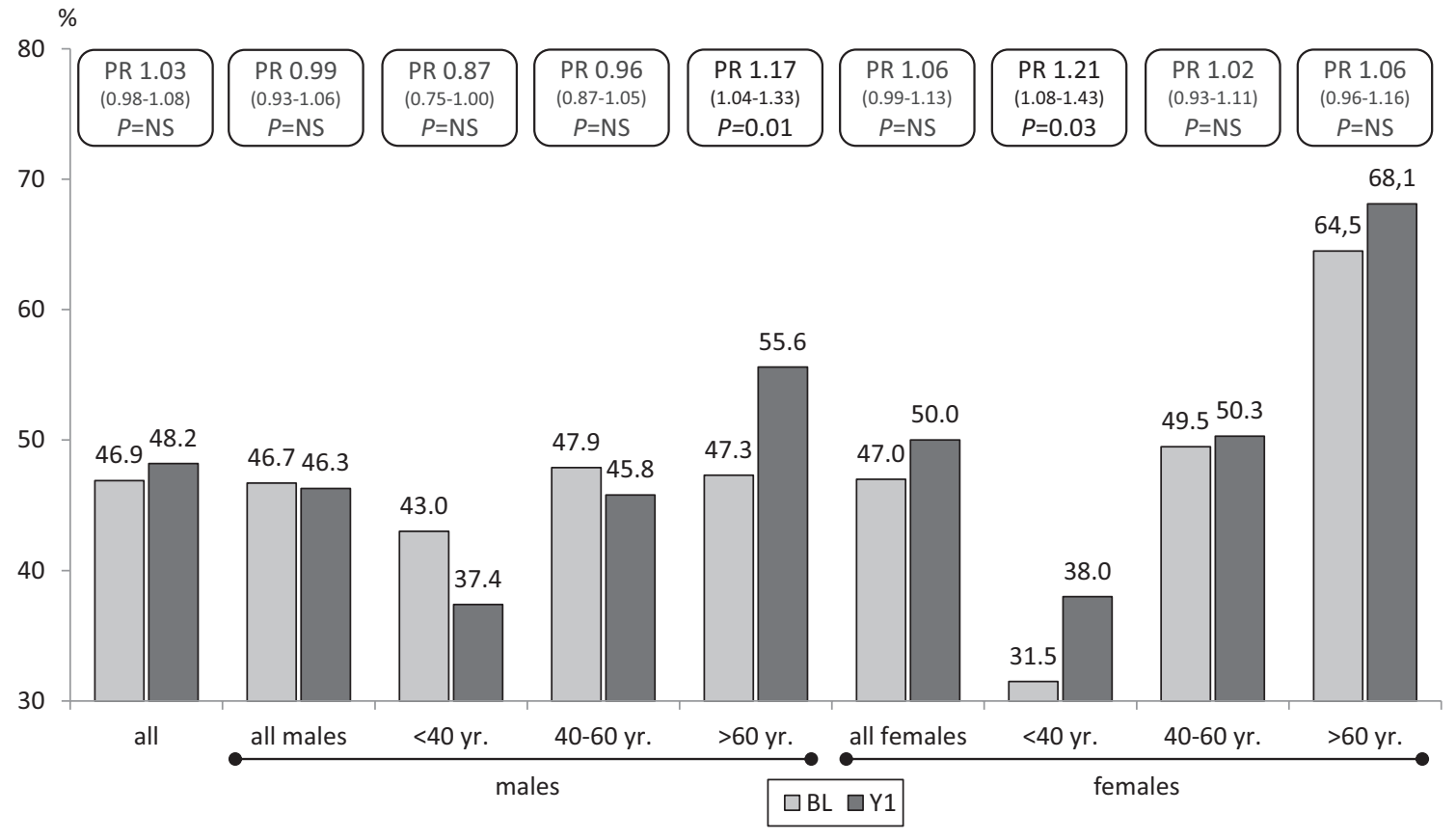

Figure 1

Prevalence ratio of MetS by gender and age category at BL and $\mathrm{Y} 1$.

The percentage of patients with abnormal waist decreased significantly at Y1 (80.3 vs $77.4 \% ; P<0.001)$, whereas impaired glucose metabolism increased (17.1 vs $23.3 \% ; P<0.001)$ as well as unfavourable HDL (48.2 vs $50.9 \% ; P=0.011)$. No change was observed for blood pressure and triglycerides. Separate analysis by gender of the prevalence of the components at Y1 showed a significant decrease in abnormal waist and triglycerides in males, but also a significant increase of impaired glucose metabolism in both males and females (Fig. 2). Similar analysis by age category indicated a significant decrease in abnormal waist in all patients $<60$ year. On the other hand, abnormal HDL increased in patients >60 year, while the increase in impaired glucose metabolism was significant in each age category (Fig. 3).

GH replacement induced in NoMS patients a positive effect on all components except for the glucose component, while this effect is only apparent for waist and systolic blood pressure in MetS patients (Fig. 4). A comparison, after adjustment for gender, age, the component value at baseline and the drug therapy, showed a significant more favourable change for all components in the NoMS group.

There was no difference between NoMS and MetS patients in the presence of TSH deficiency (77.2 vs $77.0 \%)$, ACTH deficiency (74.1 vs $72.5 \%$ ) or LH-FSH-deficiency in females (77.3 vs 76.6\%). Compared to NoMS, more MS patients had ADH deficiency (23.3 vs $26.3 \%, P=0.05)$ and

$$
\begin{array}{lr}
\text { http://www.endocrineconnections.org } & \text { O2018 The authors } \\
\text { https://doi.org/10.1530/EC-18-0096 } & \text { Published by Bioscientifica Ltd }
\end{array}
$$

LH-FSH deficiency in males (85.4 vs $89.8 \%$ ). The number of patients with isolated $\mathrm{GH}$ was equal in both groups (8.67 vs $7.58 \%, P=0.33$ ). An equal percentage of patients with NoMS and MetS were substituted for TSH deficiency (both 99.4\%), ACTH deficiency (99.0 vs 98.8\%) and LH-FSH deficiency in males (98.6 vs $98.5 \%$ ). Compared to NoMS, less MetS patients were substituted for ADH (99.2 vs $97.1, P=0.03)$ and LH-FSH deficiency in females $(88.2$ vs $76.4, P<0.001)$.

\section{Reversal of MetS status during one year of GH replacement}

While 625 patients retained their NoMS status and 553 their MetS status, a cross-over of patients was apparent in both directions: a total of 126 patients (18.5\%) switched from MetS to NoMS and 145 patients (18.8\%) switched from NoMS to MetS. Details on changes in BMI, IGF1 SDS, QoL-AGHDA, MetS score and MetS components are reported in Table 1 . Noteworthy is the finding that the dissimilarity in response was not related to a different baseline IGF1 SDS, GH replacement dose or IGF1 SDS at $\mathrm{Y} 1$, while a significant change in BMI was observed between the cross-over groups. Also of interest is the fact that the overall comparable poor QoL improved importantly and similarly irrespective of the MetS status during GH replacement.

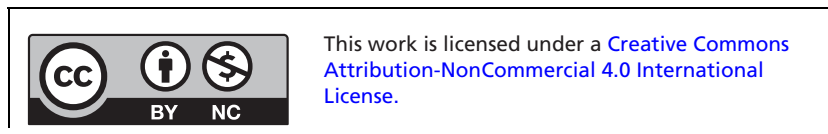




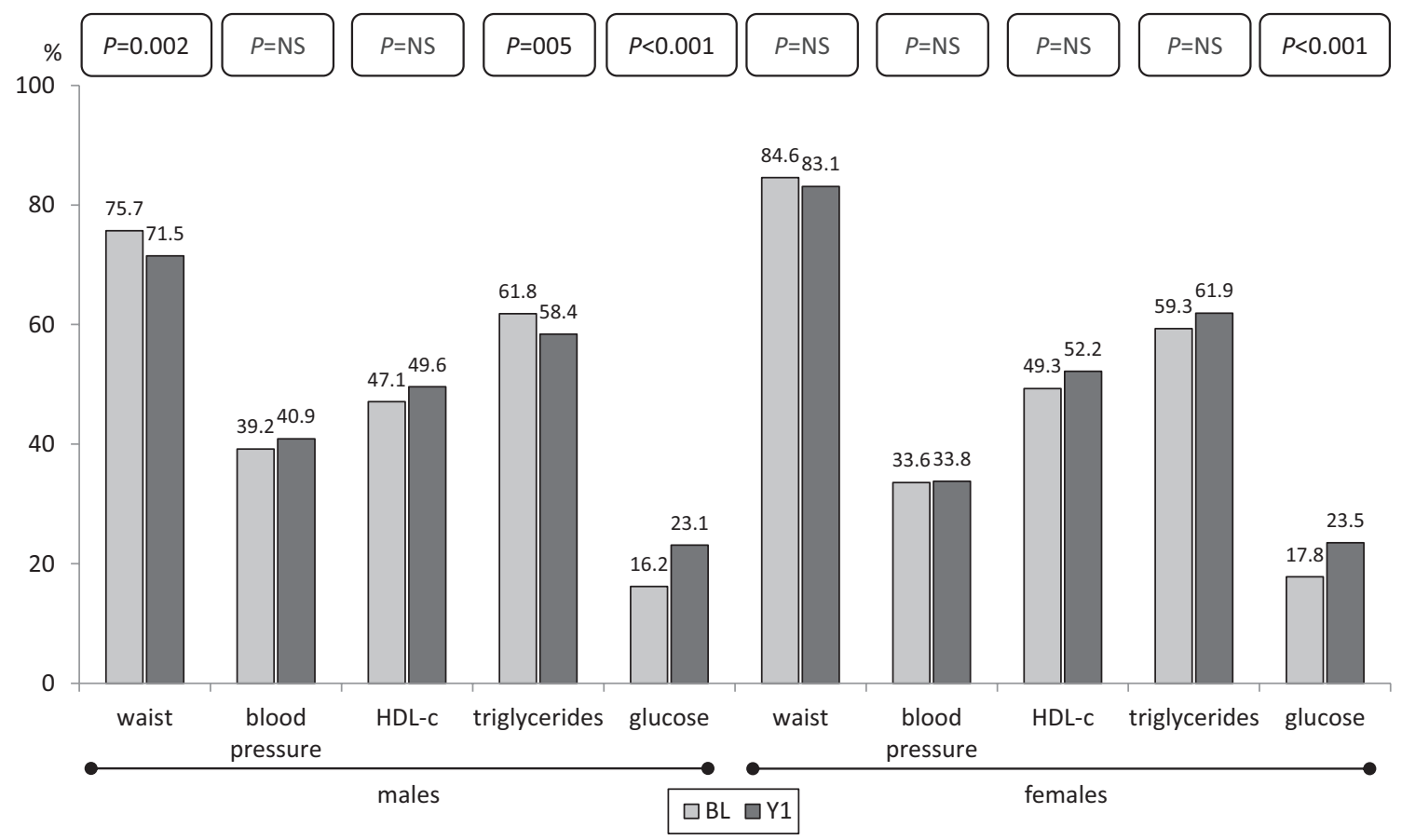

Figure 2

Prevalence of components determining MetS by gender at BL and $\mathrm{Y} 1$.

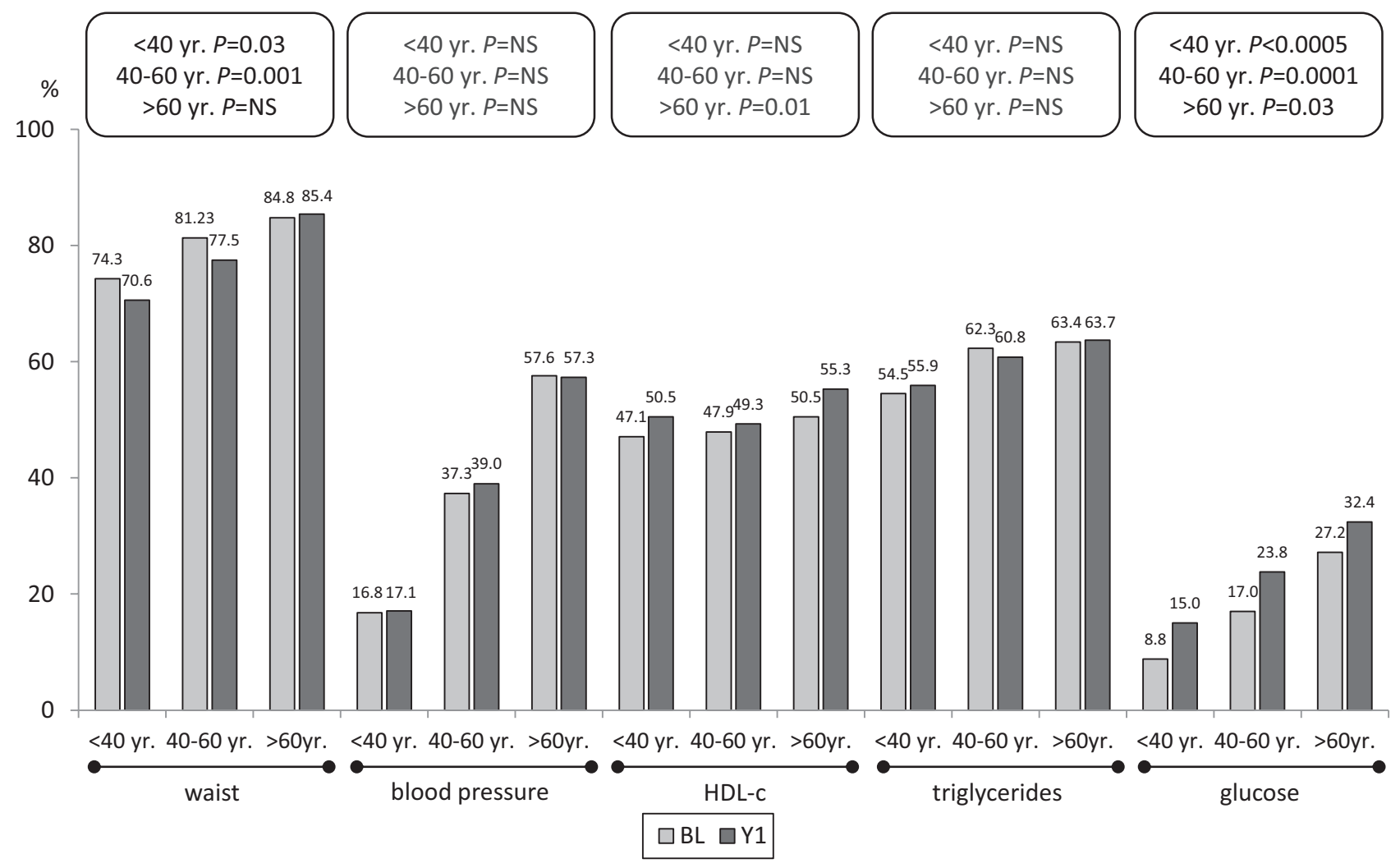

Figure 3

Prevalence of components determining MetS by age category at BL and $\mathrm{Y}$.

\begin{tabular}{|lr}
\hline http://www.endocrineconnections.org & O2018 The authors \\
https://doi.org/10.1530/EC-18-0096 & Published by Bioscientifica Ltd
\end{tabular}

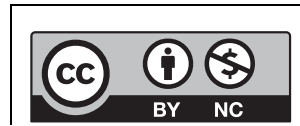

This work is licensed under a Creative Commons Attribution-NonCommercial 4.0 International License. 


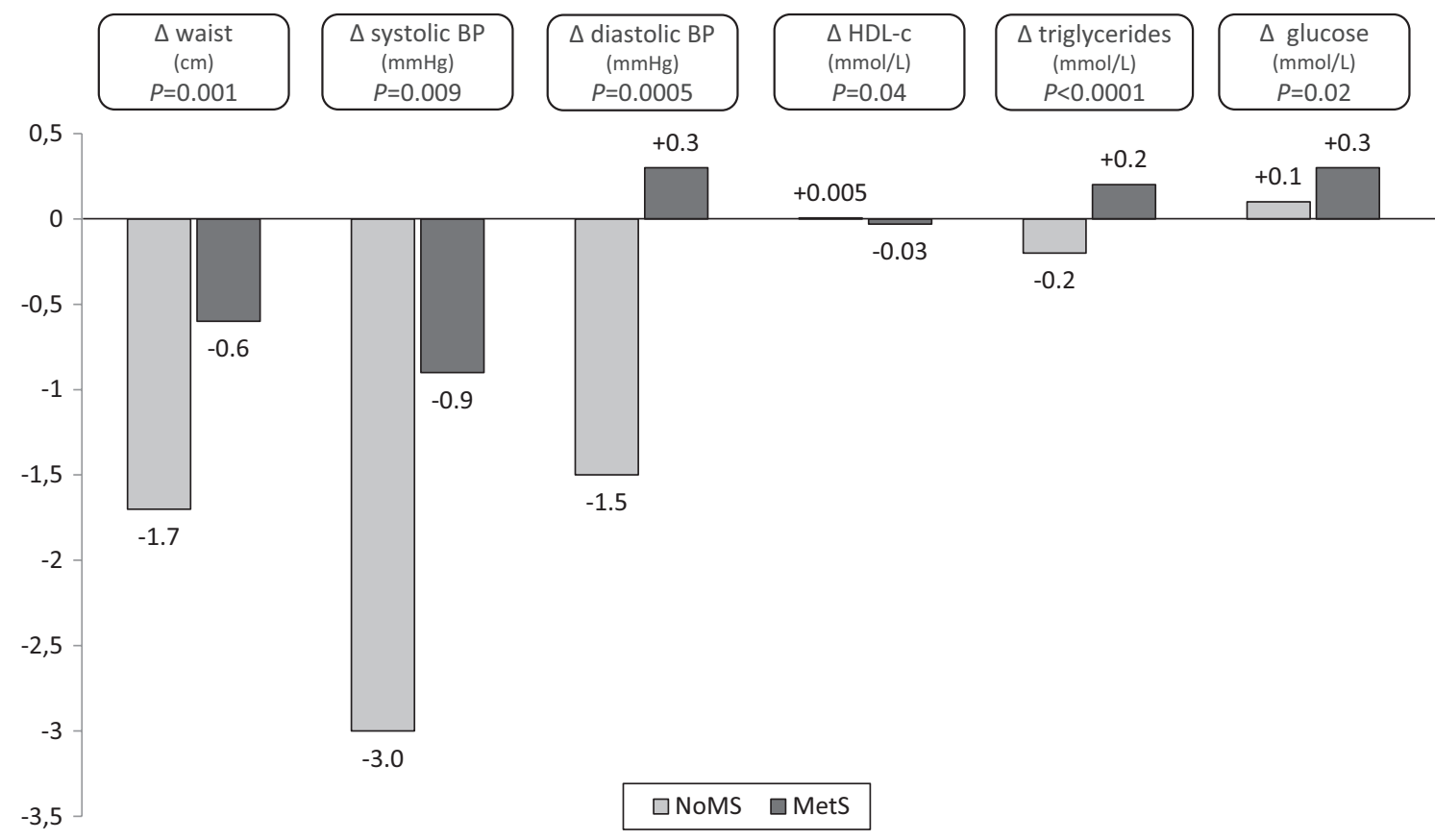

Figure 4

Changes of absolute values of MetS components at $\mathrm{Y} 1$ related to baseline MetS status.

\section{MetS at baseline and cardiovascular and} cerebrovascular events during prolonged $\mathrm{GH}$ replacement

The relative risk to develop cardiovascular events according to the presence of MetS at baseline was assessed in 3282 patients: MetS group 6.8 \pm 4.7 year of follow-up and NoMS group $7.8 \pm 5.1$ year of follow-up. Analysis of the crude incidence rate of new cardiovascular events during GH replacement showed a $66 \%$ higher risk in patients with MetS at baseline compared to NoMS patients (8.62 vs 5.19 per 1000 patient-years; relative risk (RR) 1.66; 95\% CI, 1.21-2.27). By contrast, the incidence of cerebrovascular events was, although higher, not significantly different between MetS patients and NoMS patients (3.81 vs 3.17 per 1000 patient-years; RR 1.20; 95\% CI, 0.78-1.86).

Analysis of the crude incidence rate of cardiovascular events showed a significant adverse impact of waist, blood pressure and glucose, which was confirmed for blood pressure and glucose by regression analysis (Table 2).

Assessment of the RR to develop a cardiovascular or cerebrovascular event was also determined after adjustment for gender and age (Fig. 5).

\section{Discussion}

The current findings analysing the effect of $\mathrm{GH}$ replacement on the MetS prevalence in AO-GHD patients

$$
\begin{array}{lr}
\text { http://www.endocrineconnections.org } & \text { O2018 The authors } \\
\text { https://doi.org/10.1530/EC-18-0096 } & \text { Published by Bioscientifica Ltd }
\end{array}
$$

do not permit a strict comparison with previous studies in view of different approaches $(1,2,4)$. A first premise in the present study was the use of the IDF criteria instead of the NCEP criteria, as it accords a primordial importance to the waist component known to be favourably affected by $\mathrm{GH}$ replacement. The baseline data may be compared with an European IDF reference population showing a MetS prevalence 1.30 times higher in males $(46.7 \%$ vs $35.9 \%$ ) and 1.37 times higher in females (47.0\% vs $34.1 \%$ ) (8). Another premise was to repeat the analysis after one year since the GH effect on the different components can be considered completed at that time as indicated by the normalization of IFG1 SDS. This choice allowed to include a larger number of patients, also allowing additional analyses. Nonetheless, despite the different methodology, the crude analysis of the present study confirms the fact that GH replacement does not induce an improvement in the prevalence of MetS and is thus in line with previously analysed data using the NCEP criteria over a longer period of follow-up. An overview of the different studies is given in Table 3 which also highlights the dissimilarities between the components.

Analysis of the separate components, shown in Figs 2 and 3, suggests an explanation for the failure of $\mathrm{GH}$ replacement to decrease the MetS prevalence. MetS is mostly determined by the presence of an abnormal waist, which is favourably impacted by GH replacement in both genders and in patients younger than 60 years.

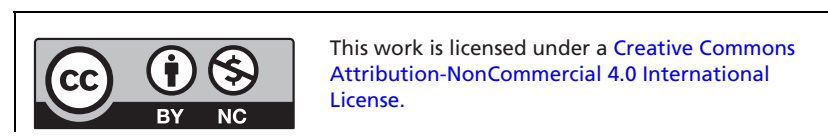


Table 1 Clinical and biochemical characteristics of GHD patients at baseline (BL) and after one year of GH replacement (Y1)

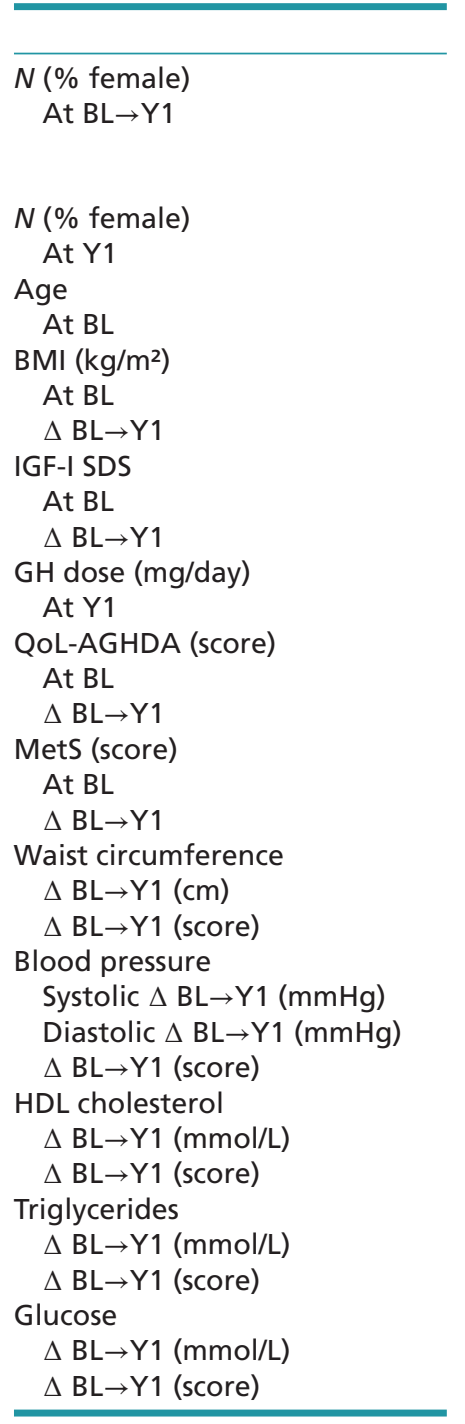

\begin{tabular}{|c|c|}
\hline \multicolumn{2}{|c|}{ NoMS } \\
\hline \multicolumn{2}{|c|}{$770(50.1) \rightarrow 751(49.2)$} \\
\hline NoMS $\rightarrow$ NoMS & MetS $\rightarrow$ NoMS \\
\hline $625(49.8)$ & $126(46.8)$ \\
\hline $46.4 \pm 13.1$ & $47.4 \pm 11.1$ \\
\hline $26.2 \pm 4.5$ & $29.8 \pm 4.4$ \\
\hline $0.0 \pm 1.4$ & $-0.4 \pm 1.6$ \\
\hline$-1.9 \pm 1.8$ & $-1.7 \pm 1.6$ \\
\hline $2.2 \pm 1.7$ & $2.0 \pm 1.5$ \\
\hline $0.4 \pm 0.2$ & $0.4 \pm 0.2$ \\
\hline $9.6 \pm 7.3$ & $10.9 \pm 7.7$ \\
\hline$-3.7 \pm 5.3$ & $-3.4 \pm 4.9$ \\
\hline $1.33 \pm 0.80$ & $3.15 \pm 0.36$ \\
\hline$-0.01 \pm 0.72$ & $-1.28 \pm 0.61$ \\
\hline$-1.7 \pm 5.5$ & $-3.1 \pm 6.1$ \\
\hline $0.59 \rightarrow 0.53$ & $1.00 \rightarrow 0.00$ \\
\hline$-1.5 \pm 14.8$ & $-2.3 \pm 17.0$ \\
\hline$-1.0 \pm 10.0$ & $-1.2 \pm 11.1$ \\
\hline $0.18 \rightarrow 0.17$ & $0.41 \rightarrow 0.27$ \\
\hline $0.0 \pm 0.3$ & $+0.1 \pm 0.2$ \\
\hline $0.18 \rightarrow 0.21$ & $0.65 \rightarrow 0.34$ \\
\hline $0.0 \pm 0.8$ & $-0.4 \pm 3.2$ \\
\hline $0.31 \rightarrow 0.32$ & $0.89 \rightarrow 0.43$ \\
\hline$+0.1 \pm 1.0$ & $-0.1 \pm 1.2$ \\
\hline $0.06 \rightarrow 0.10$ & $0.20 \rightarrow 0.08$ \\
\hline
\end{tabular}

$P$ MetS $\rightarrow$ NoMS vs
NoMS $\rightarrow$ MetS

\begin{tabular}{|c|}
\hline MetS \\
\hline $679(51.3) \rightarrow 698(53.0)$ \\
\hline NoMS $\rightarrow$ MetS $\quad$ MetS $\rightarrow$ MetS \\
\hline
\end{tabular}

0.21
NS
$<0.0001$
NS
NS
NS
NS
NS
$<0.0001$
$<0.0001$
$<0.0001$
N/A
0.03
0.007
$<0.0001$
0.01
$<0.0001$
$<0.0001$
$<0.0001$
0.03
$<0.0001$

\begin{tabular}{|c|c|}
\hline 145 (55.9) & $553(52.3)$ \\
\hline $49.2 \pm 13.3$ & $52.0 \pm 12.2$ \\
\hline $29.6 \pm 5.7$ & $31.4 \pm 5.1$ \\
\hline $0.5 \pm 2.1$ & $0.0 \pm 1.7$ \\
\hline$-1.8 \pm 1.6$ & $-1.6 \pm 1.5$ \\
\hline $2.0 \pm 1.6$ & $2.1 \pm 1.5$ \\
\hline $0.4 \pm 0.2$ & $0.3 \pm 0.2$ \\
\hline $10.4 \pm 7.0$ & $11.1 \pm 6.8$ \\
\hline$-3.3 \pm 5.5$ & $-3.5 \pm 6.0$ \\
\hline $1.81 \pm 0.57$ & $3.66 \pm 0.70$ \\
\hline$+1.48 \pm 0.62$ & $0.09 \pm 0.63$ \\
\hline$+1.4 \pm 5.9$ & $-0.9 \pm 5.5$ \\
\hline $0.78 \rightarrow 1.00$ & $1.00 \rightarrow 1.00$ \\
\hline$+2.1 \pm 18.0$ & $-1.6 \pm 17.8$ \\
\hline$+1.7 \pm 11.8$ & $-0.5 \pm 11.2$ \\
\hline $0.27 \rightarrow 0.50$ & $0.59 \rightarrow 0.60$ \\
\hline$-0.2 \pm 0.3$ & $0.0 \pm 0.2$ \\
\hline $0.26 \rightarrow 0.64$ & $0.84 \rightarrow 0.85$ \\
\hline$+0.4 \pm 1.0$ & $-0.1 \pm 1.5$ \\
\hline $0.41 \rightarrow 0.80$ & $0.93 \rightarrow 0.91$ \\
\hline$+0.3 \pm 0.7$ & $+0.2 \pm 1.3$ \\
\hline $0.10 \rightarrow 0.36$ & $0.31 \rightarrow 0.39$ \\
\hline
\end{tabular}

Table 2 Crude incidence rate (CIR, estimate and 95\% confidence limits) of cardiovascular and cerebrovascular events per 1000 patient-years during GH replacement in patients with MetS and without MetS (NoMS) at baseline and related to the presence of a specific MetS component with assessment of relative risk (RR).

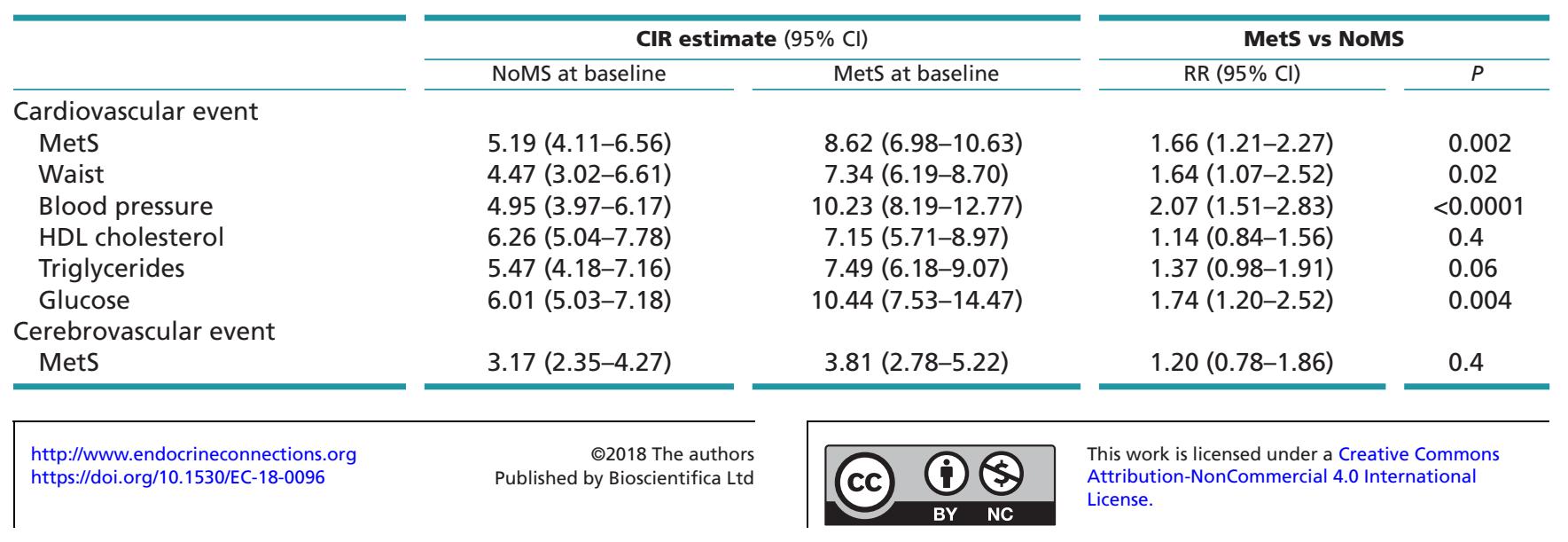




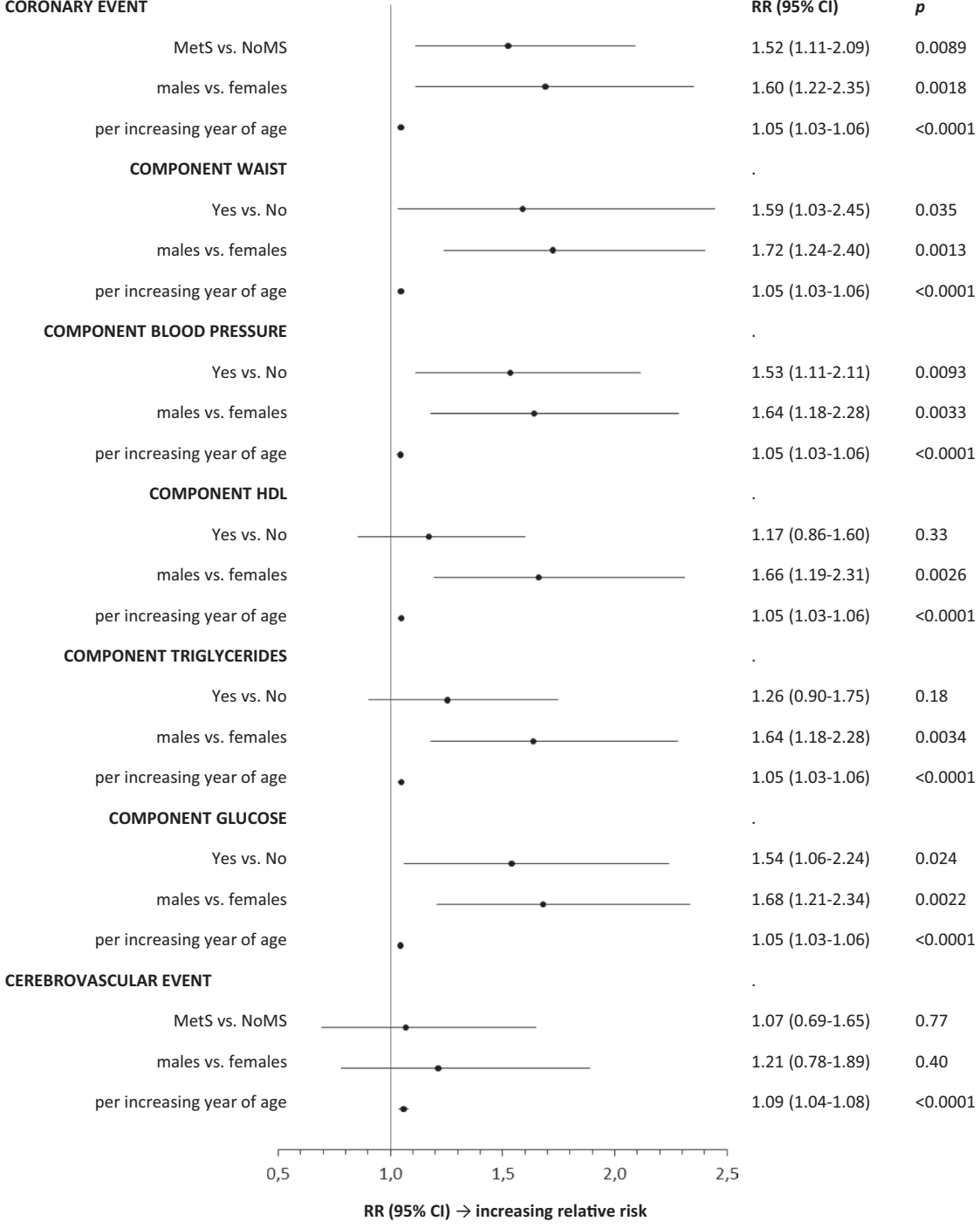

\begin{tabular}{|c|c|}
\hline RR (95\% CI) & $p$ \\
\hline $1.52(1.11-2.09)$ & 0.0089 \\
\hline $1.60(1.22-2.35)$ & 0.0018 \\
\hline $1.05(1.03-1.06)$ & $<0.0001$ \\
\hline . & \\
\hline $1.59(1.03-2.45)$ & 0.035 \\
\hline $1.72(1.24-2.40)$ & 0.0013 \\
\hline $1.05(1.03-1.06)$ & $<0.0001$ \\
\hline - & \\
\hline $1.53(1.11-2.11)$ & 0.0093 \\
\hline $1.64(1.18-2.28)$ & 0.0033 \\
\hline $1.05(1.03-1.06)$ & $<0.0001$ \\
\hline · & \\
\hline $1.17(0.86-1.60)$ & 0.33 \\
\hline $1.66(1.19-2.31)$ & 0.0026 \\
\hline $1.05(1.03-1.06)$ & $<0.0001$ \\
\hline - & \\
\hline $1.26(0.90-1.75)$ & 0.18 \\
\hline $1.64(1.18-2.28)$ & 0.0034 \\
\hline $1.05(1.03-1.06)$ & $<0.0001$ \\
\hline - & \\
\hline $1.54(1.06-2.24)$ & 0.024 \\
\hline $1.68(1.21-2.34)$ & 0.0022 \\
\hline $1.05(1.03-1.06)$ & $<0.0001$ \\
\hline $1.07(0.69-1.65)$ & 0.77 \\
\hline $1.21(0.78-1.89)$ & 0.40 \\
\hline $1.09(1.04-1.08)$ & $<0.0001$ \\
\hline
\end{tabular}

Figure 5

Assessment of the relative risk to develop a cardiovascular or cerebrovascular event after adjustment for gender and age.
However, this effect is abolished by the impaired glucose metabolism in both genders irrespective of age. This adverse effect, which mostly occurs in predisposed patients, has previously been documented and may represent an obstacle for a uniform and safe metabolic control (16, 21). Another factor that prevents a correction in the calculation of the MetS prevalence is the use at baseline of anti-hypertensive, lipid-lowering and anti-diabetic drugs, which probably are not discontinued during GH replacement. These findings question the suitability and the usefulness of establishing the diagnosis of MetS in order to express the outcome of GH replacement.

Another aspect that may influence the evaluation of $\mathrm{GH}$ replacement on the MetS prevalence is indicated by the finding, shown in Fig. 4, that patients without MetS are in a sense better GH responders than MetS patients, resulting in significantly more favourable changes for all

http://www.endocrineconnections.or https://doi.org/10.1530/EC-18-0096

2018 The authors Published by Bioscientifica Ltd five components. This behaviour reminds of a comparable observation in which overweight diabetic subjects lose less weight than their overweight nondiabetic spouses on a same weight-control program, a finding which has been confirmed afterwards $(22,23)$. This dissimilarity can be explained neither by gender, age, baseline component value and drug therapy as statistical analysis had been performed with adjustment for these variables, nor by a difference in GH dose and IGF1 change. Possibly, the prolonged metabolic changes induced by GHD in combination with MetS and a persisting propensity towards obesity are responsible for the relative unresponsiveness.

The comparative analysis of the patients crossing from one MetS status to another yields another remarkable and significant finding. As shown in Table 1, while the therapeutic conditions for the two groups were comparable regarding $\mathrm{GH}$ dose and IGF1 response, a marked 
Table 3 Overview of literature regarding the effect of GH replacement on the prevalence of MetS in AO-GHD patients and on MetS components.

\begin{tabular}{l} 
Study (reference) \\
\hline MetS definition \\
Country \\
$n$ \\
Males (\%) \\
Age (years) \\
Follow-up period (years) \\
BMI (kg/m²) \\
MetS at baseline (\%) \\
MetS at end of study (\%) \\
MetS end study vs baseline ( $P$-value) \\
Waist circumference (change) \\
Blood pressure (change) \\
HDL cholesterol (change) \\
Triglycerides (change) \\
Glucose (change)
\end{tabular}

van der Klaauw et al. (1)*
NCEP
Netherlands
50
48.0
45.2
2
26.7
38.0
42.0
NS
$=$
$=$
$=$
$=$
$=$

\begin{tabular}{l}
\multicolumn{2}{c}{ Attanasio et al. (2) } \\
\hline NCEP \\
Europe and United States \\
346 \\
53.5 \\
52.7 \\
3 \\
30.2 \\
42.5 \\
45.7 \\
NS \\
$\downarrow$ \\
$\uparrow$ \\
$=$ \\
$=$ \\
$\uparrow$ \\
\hline
\end{tabular}

\begin{tabular}{|c|c|}
\hline Claessen et al. (4) & Present study \\
\hline NCEP & IDF \\
\hline Netherlands & Europe \\
\hline 160 & 1449 \\
\hline 55.3 & 48.9 \\
\hline 54.7 & 48.9 \\
\hline 5 & 1 \\
\hline 27.5 & 29.0 \\
\hline 41.0 & 46.9 \\
\hline 53.4 & 48.2 \\
\hline 0.007 & NS \\
\hline$=$ & $\downarrow$ \\
\hline$=$ & $=$ \\
\hline$\downarrow$ in males & $\downarrow$ \\
\hline$=$ & $=$ \\
\hline$\uparrow$ & $\uparrow$ \\
\hline
\end{tabular}

*Results of 5-year follow-up not included because of overlap with the data of Claessen et al. (4).

deterioration in the group developing MetS was observed for each component. Conversely, an amelioration of each component, including impaired glucose metabolism, was observed in the group losing the adverse MetS status. This divergent course can be related to an identical baseline BMI, evolving significantly into opposite direction by gaining or losing about $0.5 \mathrm{~kg} / \mathrm{m}^{2}$. Also of importance, as shown in Table 1, is that GH replacement succeeded to significantly and similarly improve QoL in the four groups irrespective of an eventual change in MetS status and in parallel with the GH dose and IGF1 increase. The QoL-AGHDA score thus obviously evolves independently of a clinical and biochemical assessment.

The increased incidence of cardiovascular complications in GHD is well documented $(10,11,12)$. It was recently reported that GH-unreplaced patients with MetS after adjustment for age, gender and BMI had a significantly higher PR for coronary morbidity (1.91; 95\% CI, 1.33-2.75) and for cerebrovascular morbidity (1.77; 95\% CI, 1.09-2.87) than patients without MetS (3). The present study indicated that despite a prolonged GH replacement, the presence of MetS at baseline remained associated with a $66 \%$ higher incidence rate to develop new coronary events, whereas no increased incidence was found for cerebrovascular events. This finding possibly clarifies the perception that GH replacement on its own is not sufficient to normalize the enhanced cardiovascular risk induced by a longstanding GHD and that other therapeutic measures are required (3).

In conclusion, in the absence of prospective randomized trials, data from KIMS and a recent epidemiological study suggest that GH replacement is able to correct the increased mortality associated with GHD $(17,24)$. On the other hand, the present analysis using a surveillance database with its known limitations describes the absence of effect on the MetS status after one year of GH replacement and an elevated cardiovascular morbidity after seven years of follow-up (25). Possible explanations to be mentioned for this discrepancy are inadequate MetS criteria for monitoring and irredeemable metabolic damage after a too longstanding GHD. However, the present data also suggest that the model of GHD may consist of two independently evolving factors. The first one, QoL, is restored almost to normality independently of any condition. The other one, metabolic disruption, could be prevented by timely diagnosis of GHD and treated by adequate GH replacement, but it will also require a lifestyle intervention, physical activity and especially weight reduction as indicated by the cross-over patients in this study.

\section{Declaration of interest}

Johan Verhelst has received honoraria for lectures and/or advisory boards from Pfizer, Ipsen, Novartis. Anders Mattsson and Cecilia Camacho-Hübner are employed by Pfizer, Inc. All statistical analyses were performed by a statistician (Anders Mattsson). Anton Luger has received honoraria for lectures and/or advisory boards from Pfizer, Ipsen, Novo Nordisk and Eli Lilly and unrestricted grants to the Division of Endocrinology and Metabolism, Medical University of Vienna, Austria from Pfizer, Novo Nordisk and Ipsen. Roger Abs is a member of the KIMS Steering Committee. He has received grants from Pfizer, Novartis, Ipsen.

\section{Funding}

This research did not receive any specific grant from any funding agency in the public, commercial or not-for-profit sector. The KIMS database is sponsored by Pfizer Inc.
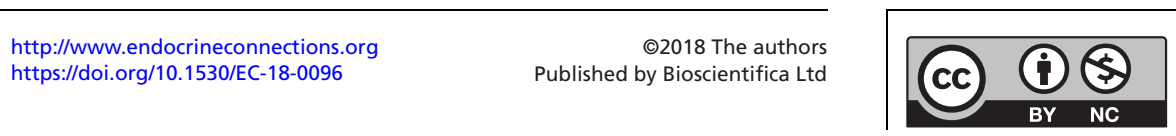


\section{References}

1 van der Klaauw AA, Biermasz NR, Feskens EJ, Bos MB, Smit JW, Roelfsema F, Corssmit EP, Pijl H, Romijn JA \& Pereira AM. The prevalence of the metabolic syndrome is increased in patients with GH deficiency, irrespective of long-term substitution with recombinant human GH. European Journal of Endocrinology 2007156 455-462. (https://doi.org/10.1530/EJE-06-0699)

2 Attanasio AF, Mo D, Erfurth EM, Tan M, Ho KY, Kleinberg D, Zimmermann AG \& Chanson P. Prevalence of metabolic syndrome in adult hypopituitary growth hormone (GH)-deficient patients before and after GH replacement. Journal of Clinical Endocrinology and Metabolism 201095 74-81. (https://doi.org/10.1210/jc.2009-1326)

3 Verhelst J, Mattsson AF, Luger A, Thunander M, Goth MI, KołtowskaHäggström M \& Abs R. Prevalence and characteristics of the metabolic syndrome in 2479 hypopituitary patients with adult-onset GH deficiency before GH replacement: a KIMS analysis. European Journal of Endocrinology 2011165 881-889. (https://doi.org/10.1530/ EJE-11-0599)

4 Claessen KM, Appelman-Dijkstra NM, Adoptie DM, Roelfsema F, Smit JW, Biermasz NR \& Pereira AM. Metabolic profile in growth hormone-deficient (GHD) adults after long-term recombinant human growth hormone (rhGH) therapy. Journal of Clinical Endocrinology and Metabolism 201398 352-361. (https://doi.org/10.1210/jc.2012-2940)

5 Gallagher EJ, Leroith D \& Karnieli E. The metabolic syndrome - from insulin resistance to obesity and diabetes. Medical Clinics of North America 201195 855-873. (https://doi.org/10.1016/j.mcna.2011.06.001)

6 Leroith D. Pathophysiology of the metabolic syndrome: implications for the cardiometabolic risks associated with type 2 diabetes. American Journal of the Medical Sciences 2012343 13-16. (https://doi. org/10.1097/MAJ.0b013e31823ea214)

7 Expert Panel on Detection, Evaluation, and Treatment of High Blood Clolesterol in Adults. Executive summary of the third report of the National Cholesterol Education Program (NCEP) expert panel on detection, evaluation, and treatment of high blood cholesterol in adults (Adult Treatment Panel III). JAMA 2001285 2486-2497. (https://doi.org/10.1001/jama.285.19.2486)

8 Alberti KG, Zimmet P \& Shaw J. Metabolic syndrome - a new worldwide definition. A consensus statement from the International Diabetes Federation. Diabetic Medicine 200623 469-480. (https://doi. org/10.1111/j.1464-5491.2006.01858.x)

9 Qiao Q \& DECODE Study Group. Comparison of different definitions of the metabolic syndrome in relation to cardiovascular mortality in European men and women. Diabetologia 200649 2837-2846. (https://doi.org/10.1007/s00125-006-0438-6)

10 Rosen T \& Bengtsson BÅ. Premature mortality due to cardiovascular disease in hypopituitarism. Lancet 1990336 285-288. (https://doi. org/10.1016/0140-6736(90)91812-O)

11 Bülow B, Hagmar L, Mikoczy Z, Nordström CH \& Erfurth EM. Increased cerebrovascular mortality in patients with hypopituitarism. Clinical Endocrinology 199746 75-81. (https://doi.org/10.104 6/j.1365-2265.1997)

12 Tomlinson JW, Holden N, Hills RK, Wheatley K, Clayton RN, Bates AS, Sheppard MC \& Stewart PM. Association between premature mortality and hypopituitarism. West Midlands Prospective Hypopituitary Study Group. Lancet 2001357 425-431. (https://doi. org/10.1016/S0140-6736(00)04006-X)

13 Maison P, Griffin S, Nicoue-Beglah M, Haddad N, Balkau B \& Chanson P. Impact of growth hormone $(\mathrm{GH})$ treatment on cardiovascular risk factors in GH-deficient adults: a meta-analysis of blinded, randomized, placebo-controlled trials. Journal of Clinical Endocrinology and Metabolism 200489 2192-2199. (https://doi. org/10.1210/jc.2003-030840)

14 Götherström G, Bengtsson BA, Bosaeus I, Johannsson G \& Svensson J. A 10-year, prospective study of the metabolic effects of growth hormone replacement in adults. Journal of Clinical Endocrinology and Metabolism 200792 1442-1445. (https://doi. org/10.1210/jc.2006-1487)

15 Abs R, Feldt-Rasmussen U, Mattsson AF, Monson JP, Bengtsson BÅ, Góth MI, Wilton P \& Kołtowska-Häggström M. Determinants of cardiovascular risk in 2589 hypopituitary GH-deficient adults - a KIMS database analysis. European Journal of Endocrinology 2006155 79-90. (https://doi.org/10.1530/eje.1.02179)

16 Luger A, Mattsson AF, Kołtowska-Häggström M, Thunander M, Góth M, Verhelst J \& Abs R. Incidence of diabetes mellitus and evolution of glucose parameters in growth hormone-deficient subjects during growth hormone replacement therapy: a long-term observational study. Diabetes Care 201235 57-62. (https://doi. org/10.2337/dc11-0449)

17 Gaillard RC, Mattsson AF, Åkerblad AC, Bengtsson BÅ, Cara J, Feldt-Rasmussen U, Kołtowska-Häggström M, Monson JP, Saller B, Wilton $\mathrm{P}$, et al. Overall and cause-specific mortality in GH-deficient adults on GH replacement. European Journal of Endocrinology 2012 166 1069-1077. (https://doi.org/10.1530/EJE-11-1028)

18 Riis P. Thirty years of bioethics: the Helsinki declaration 1964-2003. New Review of Bioethics 20031 15-25. (https://doi.org/10.1080/17400 28032000131396)

19 McKenna SP, Doward LC, Alonso J, Kohlmann T, Niero M, Prieto L \& Wirén L. The QoL-AGHDA: an instrument for the assessment of quality of life in adults with growth hormone deficiency. Quality of Life Research 19998 373-383. (https://doi. org/10.1023/A:1008987922774)

20 International Diabetes Federation, Clinical Guidelines Task Force. Screening and diagnosis. In Global Guideline for Type 2 Diabetes, pp 9-14. Brussels, Belgium: IDF, 2012. (available at: https://www.iapb. org/wp-content/uploads/Global-Guideline-for-Type-2-DiabetesIDF-2012.pdf)

21 Abs R, Mattsson AF, Thunander M, Verhelst J, Góth MI, Wilton P, Kołtowska-Häggström M \& Luger A. Prevalence of diabetes mellitus in 6050 hypopituitary patients with adult-onset GH deficiency before GH replacement: a KIMS analysis. European Journal of Endocrinology 2013168 297-305. (https://doi.org/10.1530/EJE-12-0807)

22 Wing RR, Marcus MD, Epstein LH \& Salata R. Type II diabetic subjects lose less weight than their overweight nondiabetic spouses. Diabetes Care 198710 563-566. (https://doi.org/10.2337/diacare.10.5.563)

23 Guare JC, Wing RR \& Grant A. Comparison of obese NIDDM and nondiabetic women: short- and long-term weight loss. Obesity Research 19953 329-335. (https://doi.org/10.1002/j.1550-8528.1995. tb00158.x)

24 Olsson DS, Trimpou P, Hallén T, Bryngelsson IL, Andersson E, Skoglund T, Bengtsson BÅ, Johannsson G \& Nilsson AG. Life expectancy in patients with pituitary adenoma receiving growth hormone replacement. European Journal of Endocrinology 2017176 67-75. (https://doi.org/10.1530/EJE-16-0450)

25 Gutiérrez LP, Kołtowska-Häggström M, Jönsson PJ, Mattsson AF, Svensson D, Westberg B \& Luger A. Registries as a tool in evidencebased medicine: example of KIMS (Pfizer International Metabolic Database). Pharmacoepidemiology and Drug Safety 200817 90-102. (https://doi.org/10.1002/pds.1510) http://www.endocrineconnections.org https://doi.org/10.1530/EC-18-0096
()2018 The authors Published by Bioscientifica Ltd
Received in final form 5 March 2018

Accepted 16 April 2018

Accepted Preprint published online 16 April 2018 